\title{
Deposition and Characterization of the Titanium-Based Coating by a Multi-Chamber Detonation Sprayer
}

\author{
Arseenko M.Yu. ${ }^{1, a^{*}}$, Tyurin Yu.N. ${ }^{2, b}$, Prozorova M.S. ${ }^{1, c}$, Kovaleva M.G. ${ }^{1, d}$, \\ Novikov V.Yu. ${ }^{1, \mathrm{e}}$, Yapryntsev M.N. ${ }^{1, \mathrm{f}}$, Sirota V.V. ${ }^{1 \mathrm{~g}}$, Pavlenko I.A. ${ }^{1, \mathrm{~h}}$ \\ ${ }^{1}$ Belgorod State National Research University, Pobeda str., 85, 308015, Belgorod, Russia \\ ${ }^{2}$ E. O.Paton Electric Welding Institute, NASU, Bozhenko str., 11, 03680, Kiev, Ukraine \\ ${ }^{3}$ N.N. Semenov Institute of Chemical Physics, RAS, Kosygin str., 4, 119991, Moscow, Russia
}

\begin{abstract}
This work introduces some of the aspects of the deposition of titanium-based coating (80-120 $\mu \mathrm{m}$ thick) on aluminium samples using a multi-chamber detonation sprayer (MCDS). The characteristic feature of MCDS is that the powder is accelerated by using combustion products that are formed in MCDS chambers and are converged before entering the nozzle, where they interact with the two-phase gas-powder cloud. The microstructures and properties of the coating were characterized with the use of scanning electronic microscopes (SEM), optical microscope (OM), Xray Diffraction (XRD) techniques, and Vickers hardness tester with a $50 \mathrm{~g}$ test load. Wear tests were carried out using a computer controlled pin-on-disc type tribometer. It was established that MCDS has provided the conditions for formation of a dense titanium-based coating with a porosity of less than $1.0 \%$, microhardness $810 \pm 250 \mathrm{HV} 0.05$ and a specific wear rate of $2.077 \cdot 10-4 \mathrm{~mm} 3(\mathrm{~m} \cdot \mathrm{N})-1$.
\end{abstract}

\section{Introduction}

In view of better physical-mechanical properties of titanium and its compounds, it is of interest to deposit a coating of titanium-base materials on aluminium [1]. Due to unique properties of titanium the titanium based coatings are commonly used in aircraft, pipes for power plants, armour plating, naval ships, spacecraft and missiles [2]. At present the titanium coatings are produced by thermal spray methods such as air plasma spraying (APS) [3], chemical vapour deposition (CVD) [4], high velocity oxy-fuel (HVOF) [5], cold-sprayed [6], warm spray [7] and others. The critical velocity necessary to form the bonding of powder and substrate is relatively high for titanium due to its lower deformability related to its hcp crystal structure [8]; the reported microstructures of titanium coating tend to be porous as compared to more easily sprayable materials such as copper and aluminium. Therefore, the development of new methods for making thick coatings of titanium with high density is indispensable for many industrial applications [9]. The aim of this paper is to investigate the microstructure and properties of titanium-based powder coating was obtained on aluminium substrate through a new method of powder acceleration which allows achieving the powder velocity of $1400 \mathrm{~m} / \mathrm{s}$.

\section{Experimental Procedure}

Powder titanium PTS-2 (POLEMA JSC, Russia) (d(0.1): $11.29 \mu \mathrm{m}, \mathrm{d}(0.5): 48.63 \mu \mathrm{m}, \mathrm{d}(0.9): 91.31 \mu \mathrm{m})$ (Fig. 1 ) was used to deposit a dense layer on a plate with dimensions of $30 \times 30 \times 5(\mathrm{~mm})$ of the aluminum substrate. The particle size was measured by laser diffractometry Analysette 22 NanoTec. The titanium powder of the phase composition and structure tested by XRD have certified at angles $2 \theta$ of 10 to 1000 by scanning with step $\Delta(2 \theta)=0.020$, and an exposure time of 2.5 seconds at a point on a diffractometer Rigaku Ultima IV $(\mathrm{Cu}-\mathrm{K} \alpha, \lambda=0,154059 \mathrm{~nm})$. The phase analysis shows that the main phase in the titanium powder is $\mathrm{Ti}$ with a hexagonal lattice structure $(\mathrm{a}=\mathrm{b}=2.94 \AA$, $\mathrm{c}=$ $4.68 \AA$ ) (Fig. 2). Flat specimens of aluminum alloy AD31 (Fe-0.35Cr-0.06Cu-0.10Mg-0.05Ti-0.15, all in wt \%) were used as substrates, and they were sandblasted by an alumina grits 25A F360 prior to spraying. The specimens were transversally cut by spark erosion, mechanically polished and prepared by standard metallographic sample preparation sectioning, mounting and polishing methods. This involved a grinding with abrasive $\mathrm{SiC}$ paper $(200$, 500,800 and 1,000 grades). The specimens were then polished using 6,3 and 1-micron diamond polishes on a lubricated cloth.

\footnotetext{
*a arseenko@mail.ru, ${ }^{b}$ y.n.tyurin@rambler.ru, ${ }^{c}$ prozorova@bsu.edu.ru, ${ }^{\mathrm{d}}$ kovaleva@bsu.edu.ru,

evseslav_novikov@mail.ru, ${ }^{\mathrm{f}}$ yaprintsev@bsu.edu.ru, ${ }^{\mathrm{g}}$ sirota@bsu.edu.ru, ${ }^{\mathrm{h}}$ dancer.disco@mail.ru
} 


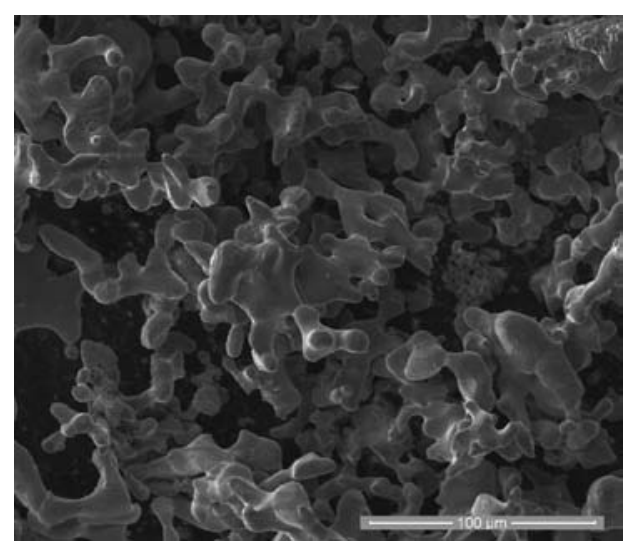

(a)

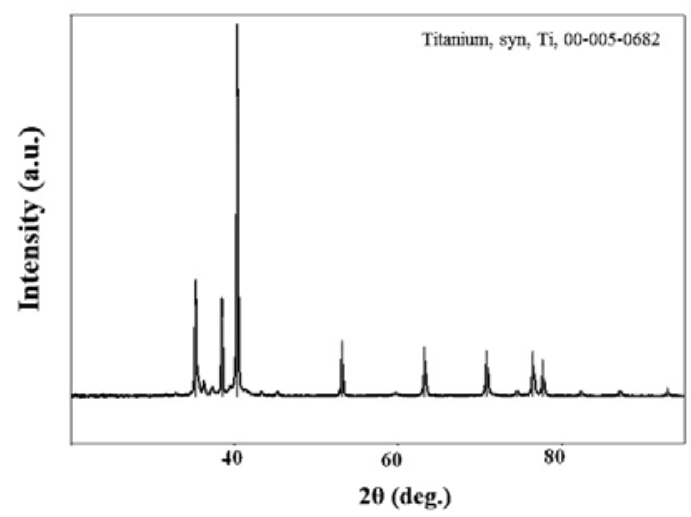

(b)

Fig. 1. The titanium powder: SEM image (Quanta 200 3D) (a), XRD pattern (b)

In the present study, a multi chamber, vertically mounted, detonation sprayer (MCDS) [10,11] with a barrel length of $500 \mathrm{~mm}$ was employed to deposit the titanium powder coatings upon an aluminium substrate. The characteristic feature of MCDS is that the powder is accelerated by using the combustion products that are formed in the MCDS chambers and are converged before entering the barrel, where they interact with the two-phase gas-powder cloud. A standard powder feeder from Metco Company is used to feed powder to the barrel.

The titanium-based coatings were deposited with a frequency of $20 \mathrm{~Hz}$. The movement speed was $2500 \mathrm{~mm} / \mathrm{min}$, the distance from the exit section of the barrel to the treated plate was $60 \mathrm{~mm}$, and diameter of the barrel was $16 \mathrm{~mm}$. A barrel with a throat diameter of 16 $\mathrm{mm}$ was adopted. The flow rate of the fuel mixture components $(\mathrm{m} 3 / \mathrm{h})$ was oxygen $(2.48 * / 3.04 * *)$, propane
$30 \%$ +butane $70 \% 0.59 * / 0.75 * *)$ and, air $(1.37 * / 1.56 * *)$ (*cylindrical form combustion chamber, **combustion chamber in the form of a disk).

The microstructure and elemental composition of the powder and coatings were determined by using the microscopes Quanta 200 3D (SEM) and Olympus GX 51 (OM). Porosity was determined by the metallographic method with elements of the qualitative and quantitative analysis of the geometry of the pores by using Olympus GX51. Ten arbitrarily selected micrographs for each experimental point were registered with an optic microscope (bright field, magnified 500x) using "SIAMS Photolab" programme. A local phase analysis was conducted by using X-ray powder diffractometer Rigaku Ultima IV. Micro-hardness was measured with an automatic DM-8B (Affri) micro-hardness tester using a Vickers's test with a $50 \mathrm{~g}$ test load. Indentation was carried out on cross-sections of the samples of the coatings. The tribological evaluations of the coated substrates under dry conditions were performed using a ball on disc tribometer CSM Instruments according to ASTM wear testing standard G-99. A $6 \mathrm{~mm}$ in diameter aluminum oxide (A12O3) ball was used as a counterbody. Specimens were tested under a $10 \mathrm{~N}$ normal load, 0.15 $\mathrm{m} \cdot \mathrm{s}-1$ sliding speed and a total sliding distance of $1000 \mathrm{~m}$. The total wear volume was calculated by measuring the track cross-sectional area with a stylus profilometer (Taylor-Hobson) at ten different locations along the wear track. The ASTM G-99 standard determines the amount of wear by measuring the appropriate linear dimensions of both specimens (ball and disk) before and after the test [12]. On average, 10 tests were used as an indicator of the coating hardness and wear resistance. The all obtained samples are characterized by almost the same microstructures and properties. Arbitrary selected data are presented in the paper.

\section{Results and discussion}

The thickness of deposited coatings ranged about 80-120 $\mu \mathrm{m}$. As shown by examinations of microstructure of a transverse section of a coated sample (Fig. 2), the titanium-based coating is uniform and dense, and has a good adhesion to the substrate. The bulk of the coating material is deformed and closely packed. The porosity of the titanium-based coating was $0.84 \%$. The interface between the coating and the substrate had no visible macro defects. 

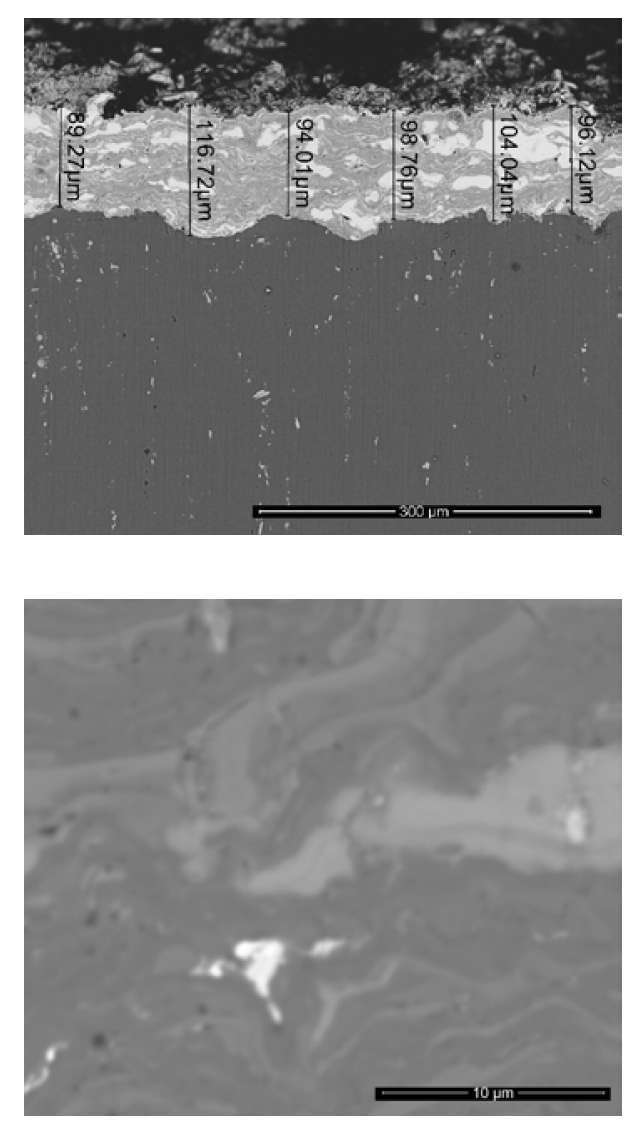

(a)

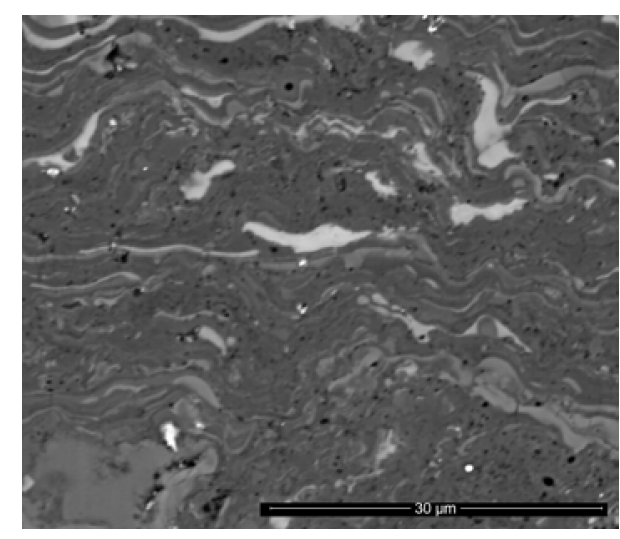

(a)

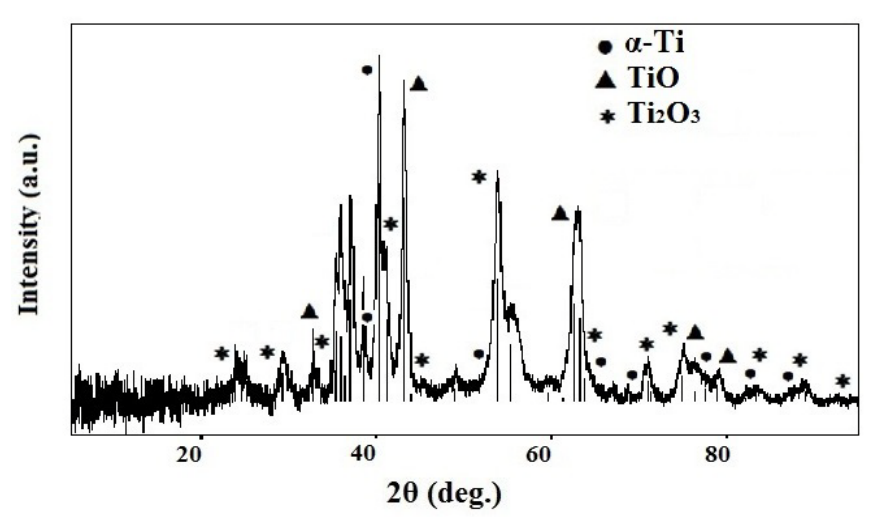

(b)

Fig. 2. SEM cross section images (back-scattered electron mode) (a) and XRD pattern (b) of the titanium-based coating

The coating is formed through the successive layering of a set of deformed particles with different temperatures, speeds and masses. The dense coating was formed through the intensive plastic deformation resulting from the impact of a particle moving with high velocity and the tamping effect on the source side of the following particles.

It was established that hardness of the titanium-based coatings was $810 \pm 250 \mathrm{HV} 0.05$, this being 6-7 times higher than that of the aluminium substrate material $125 \pm 4 \mathrm{HV} 0.05$. Also, a wide range of hardness values in obtained coatings is caused by their different phase composition and porosity.

Fig. 2,b shows the XRD patterns of the titanium-based coating. Crystalline phases were identified using the ICCD PDF-2 (2008) powder diffraction database. The phase analysis shows that after spraying the main phase in the coatings layer is $\alpha-\mathrm{Ti}$ (DB card number 01-089-5009). The distinguished interplanar spacing's calculated from the reflections make it possible to identify the following phases in the coating: TiO (DB card number 00-0080117), Ti2O3 (DB card number 00-010-0063) and Cr0.222Ti0.77801.889 (DB card number 00-030-0415). A specific wear rate of titanium-based coating was as low as $2.077 \cdot 10-4 \mathrm{~mm} 3(\mathrm{mNN})-1$. This is much less than a specific wear rate of an aluminum alloy AD31 (14.445 $\mathrm{mm} 3(\mathrm{~m} \cdot \mathrm{N})-1)$.

\section{Summary}

The titanium-based coating on the flat specimens of aluminum alloy $\mathrm{AD} 31$ was produced by a multi-chamber detonation sprayer. A dense layer at lamellas and deformed titanium particles with porosity of less than $1.0 \%$ was formed on the sample surface. The titaniumbased coating has a hardness of $810 \pm 250 \mathrm{HV} 0.05$ and specific wear rate of $2.077 \cdot 10-4 \mathrm{~mm} 3(\mathrm{~m} \cdot \mathrm{N})-1$. The results of this work open up new prospects for the further elaboration of new technologies for making titaniumbased coating that can enhance the properties of aluminum alloy.

\section{Acknowledgements}

The study was financial supported by the Russian Science Foundation, under grant No.15-19-00189. All of studies were carried out by the scientific equipment of the joint research center "Diagnostics of structure and properties of nanomaterials" of Belgorod National Research University what is financially supported with Ministry of Science and Education of RF under project № 14.594.21.0010, unique code RFMEFI59414X0010. 


\section{References}

1. D.K. Christoulis, S. Guetta, V. Guipont and M. Jeandin: J. Therm. Spray Technol. Vol. 20(3) (2011), p. 523.

2. J.A. Mountford: Titanium - Properties, advantages and applications solving the corrosion problems in marine service (Jr. Paper number 02170 presented in Corrosion 2002).

3. W. Zhao, C. Liu, L. Dong and Y. Wang: J. Therm. Spray Technol. Vol. 18(4) (2009), p. 702.

4. A.C. Jones, M.L. Hitchman: Chemical vapor deposition: precursors, processes and applications, chapter, 1, RSC Publishing, (2008).

5. J. Kawakita, S. Kuroda, T. Fukushima and H. Karanoda: Surf. Coat. Technol. Vol. 3-4(201) (2006), p. 1250.

6. H.R. Wang, B.R. Hou, J. Wang, Q. Wang and W.Y. Li: J. Therm. Spray Technol. Vol. 17(5-6) (2008), p. 736.
7. K.-H. Kim, S. Kuroda, M. Watanabe, R.-Z. Huang, H. Fukanuma and H. Katanoda: J. Therm. Spray Technol. Vol. 21(3-4) (2012), p. 550.

8. T. Schmidt, F. Gartner, H. Assadi, and H. Kreye: Acta Mater. Vol. 54(3) (2006), p. 729.

9. A. Papyrin, V. Kosarev, S. Klinkov, A. Alkhimov and V. Fomin: Cold spray technology (Elsevier, Amsterdam 2007).

10. N. Vasilik, N. Tyurin, O. Kolisnichenko, Method for gas-dynamic detonating speedup of powders and device for its implementation, RU Patent 2506341, 2012.

11. M. Kovaleva, Yu. Tyurin, N. Vasilik, O. Kolisnichenko, M. Prozorova, M. Arseenko, V. Sirota, I. Pavlenko, J. Therm. Spray Technol. Vol. 23(7) (2014) p. 1199.

12. Standard test method for wear testing with a Pin-onDisk apparatus, ASTM G99-05(2010), Book of ASTM Standards, American Soc. for Metals, (2010) 